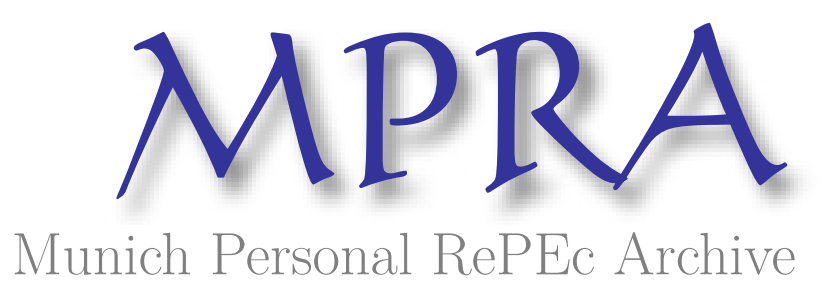

\title{
Indian Agriculture in the New Economic Regime, 1971-2003: Empirics based on the Cobb Douglas Production Function
}

Kamat, Manoj and Tupe, Sanjay and Kamat, Manasvi

Indian Institute of Technology Bombay, Goa University

February 2007

Online at https://mpra.ub.uni-muenchen.de/6150/

MPRA Paper No. 6150, posted 07 Dec 2007 14:33 UTC 


\title{
Indian Agriculture in the New Economic Regime, 1971-2003: Empirics based on the Cobb Douglas Production Function
}

\author{
Manoj S. Kamat ${ }^{\mathbf{a}}$ \\ Sanjay N. Tupe ${ }^{\mathbf{b}}$ \\ Manasvi M. Kamat ${ }^{\mathbf{c}}$
}

February 2007

\begin{abstract}
This paper reviews the trends in Indian Agriculture before and after the introduction of the economic reforms, and the advent of WTO regime. We employ the Cobb Douglas Production Function using the OLS specification to investigate the determinants of agricultural gross domestic product for the period 1970-71 to 2002-03, during pre and posteconomic reforms to document the impact of policy change (post-1992) and India's membership of the WTO (post-1995). Our empirical findings reveal that Indian agriculture sector has witnessed Decreasing Returns to Scale after the introduction of economic reforms, indicating that the input availability is under strain during the same period.
\end{abstract}

Keywords: Agriculture Gross Domestic Product, WTO, Economic Reforms, Trends, Determinants, Returns to Scale, Cobb Douglas Production Function, India.

Manoj Subhash Kamat ${ }^{\mathbf{a}}$ and Sanjay Tupe ${ }^{\mathbf{b}}$ are Research Scholars at the Dept. of Humanities and Social Sciences, Indian Institute of Technology Bombay. Manasvi Kamat ${ }^{\mathbf{c}}$ is a Research Scholar in Economics at Shree Damodar College of Commerce \& Economics, Margao-Goa.

Correspondence: Manoj Subhash Kamat mskamat@iitb.ac.in 


\title{
Indian Agriculture in the New Economic Regime, 1971-2003: Empirics based on the Cobb Douglas Production Function
}

\author{
By \\ Manoj S. Kamat, Sanjay N. Tupe, and Manasvi M. Kamat
}

\section{Introduction}

The importance of agriculture sector in the process of economic development is indispensable. With the recognition of this fact, Indian planners have emphasized on the development of agricultural and allied sector right from the beginning of the economic planning process in India. In the last 57 years, Indian agriculture has significantly contributed in terms of income and employment generation. Even today the $24 \%$ of the total GDP (Gross Domestic Product) originates from the agriculture sector and $62 \%$ people find direct and indirect employment in the agriculture sector in India. However in the process of economic transformation, agriculture sector looses its importance due to its eroding contribution in national income, Lewis (1954), Syrgnin (1988). This has been exactly happening in India, as 55\% of the total National Income coming from agriculture sector in 1951 today is currently stuck to mere $24 \%$. Structural transformation is inevitable in the country if the economic planning is pursed as a way of development. Several policy initiatives have brought the changes in Indian economy in scale of production of food grain, cropping pattern and productivity in agriculture sector.

New Economic Policy 1991 and the formation of WTO in 1995 have brought structural transformations in the Indian agricultural sector. This paper attempts to review trends in this since 1970-71 periods. It also examines the determinants of agricultural gross domestic product during the pre and post-economic reforms. The entire study is divided into 5 sections. Section one, examines the trends in the Indian in the last 32 years with a special emphasis on the impacts of reforms and India's membership of the WTO. Section two reviews the literature. Section three deals with data and methodology, Section four discusses the results of empirical study while the final Section five summaries and offers policy suggestions. 


\section{Trends in Indian Agriculture}

a. Production of Food Grains: In the earlier years of economic planning, food availability was the serious problem in India. The total food grain production was hardly 51 million tones in 1950-51, which increased to 216 million tones in 2004-05. Ninth Five Year Plan (1997-2002) emphasized on building of food stock to take up the challenge of famine and ever increasing demand for food from the masses. However the average Compounded Annual Growth Rate (CAGR) of agriculture and the allied sector remained low and volatile since the beginning of the said Plan. In the Eight Plan (1992-97) average annual growth rate of agriculture was 4.7 percent, which declined to 2.1 per cent in Ninth Plan (1992-2002). Tenth Plan (2002-07) targets 4 per cent growth rate of agriculture sector which seem to be difficult to achieve due to the severe drought of 2002-03, some adversity and lack of special supportive policies for boosting production of food grains.

Table 1. Trends in Production of Major Food Grain Crops (In percentages).

\begin{tabular}{|c|c|c|c|}
\hline \multirow{2}{*}{ Crops } & \multicolumn{2}{|c|}{ Before Economic Reforms } & After Reforms \\
\hline & $1970-71$ to $1980-81$ & $1981-82$ to $1992-93$ & $1993-94$ to $2004-05$ \\
\hline Rice & 2.42 & 0.37 & -2.38 \\
\hline Wheat & 4.36 & 4.33 & 1.37 \\
\hline Coarse Cereals & -0.5 & 1.64 & 0.75 \\
\hline Pulses & -1.06 & 0.65 & -0.2 \\
\hline $\begin{array}{l}\text { Total Food Grain } \\
\text { Production }\end{array}$ & 1.80 & 3.00 & 0.67 \\
\hline
\end{tabular}

Note: The compounded annual growth (CAGR) rate has been calculated by using the semi-log model such as $\ln Y_{\mathrm{t}}=\beta_{1}+\beta_{2} t+\mu_{\mathrm{t}}$, where variable $Y_{\mathrm{t}}$ represents the production time-series of the particular crop, $t$ measures the time period and $\mu_{\mathrm{t}}$ is the error term. Data Source: Hand Book on Indian Statistics 2005-06, Reserve Bank of India.

Table 1 reveals the trends in food grain production of major crops for pre and posteconomic reform periods. It can be seen from the table that CAGR of production of rice crop declines from 2.42 between the eighties and further declines to -0.08 percent in nineties. Production of Wheat also declines from 4.36 to 1.37 for the period 1970-71 to 2002-03. The CAGR of Coarse Cereals and Pulses is negative in the decade of 1970s however has slightly picked up in 1980s due to the constitution of Oil Seed Mission and its sustained efforts; again it is suffered with a rate of decay in the decade of 1990s. Consequentially, Total food grain production growth declines from 3.00 percent in the $1980-90$ decade to 0.67 percent during the post-reform periods. If this declining trend continues, food security would be the great challenge in near future for India. It is therefore that there is an ardent need to have 
again the Green Revolution movement in India to attain the 8 percent proposed growth rate of GDP in $10^{\text {th }}$ Five Year Plan.

b. Trends in Cropping Pattern: A change in cropping pattern indicates a shift in area under the cultivation of major crops. Since 1950-51 the area under food grain crop cultivation has been declining, also indicating that the cultivation of non-food grain crops has been increasing. In 1950-51 the area under food grain crop cultivation was 74 percent of the cultivable land, which declined by 2 percent to 72 percent in 2002-03. This shift in cropping pattern was taking place due remunerative prices being offered to commercial crops and better market access given to growers. The trend in cropping pattern is depicted in Table 2; and it is evident that after the introduction of new economic policy the area under cultivation of the rice and wheat crops decelerated from 0.66 and 2.02 in 1970 s to -0.08 and 0.51 in the decade 1990s respectively. Area devoted for the coarse cereals and pulses also decreases during the same duration. Total area under major crops also decreased from 0.19 to -0.28 percent. Declining trend in all these crops created shortage of food in the recent days and puts pressure on prices of daily foodstuff, resulting into increasing cost of living of masses.

Table 2. Area under Cultivation of Major Crops (In Million Hectares)

\begin{tabular}{|c|c|c|c|}
\hline \multirow{2}{*}{ Crops } & \multicolumn{2}{|c|}{ Before Liberalization } & After Liberalization \\
\cline { 2 - 4 } & $\mathbf{1 9 7 0 - 7 1}$ to 1980-81 & $\mathbf{1 9 8 1 - 8 2}$ to 1992-93 & $\mathbf{1 9 9 3 - 9 4}$ to 2004-05 \\
\hline Rice & 0.66 & 0.26 & -0.08 \\
\hline Wheat & 2.02 & 1.06 & 0.51 \\
\hline Coarse Cereals & -0.79 & -1.59 & -1.09 \\
\hline Pulses & -0.04 & 0.64 & 0.09 \\
\hline Total Area & $\mathbf{0 . 1 9}$ & $\mathbf{- 0 . 5 1}$ & $\mathbf{- 0 . 2 8}$ \\
\hline
\end{tabular}

Note: The compounded annual growth (CAGR) rate has been calculated by using the semi-log model such as $\ln Y_{\mathrm{t}}=\beta_{1}+\beta_{2} t+\mu_{\mathrm{t}}$, where variable $Y_{\mathrm{t}}$ represents the production time-series of the particular crop, $t$ measures the time period and $\mu_{\mathrm{t}}$ is the error term. Data Source: Hand Book on Indian Statistics 2005-06, Reserve Bank of India.

\section{Literature Review}

The impact of the New Economic Policy on the state of Indian agriculture with reference to socio-economic factors like poverty, farmers suicides, food stock, input support, quantum of production, cropping pattern are documented by the various authors, however the impact of new economic policy and India's membership of the WTO on agricultural growth is not documented in the earlier studies. Hence this paper addresses this gap and explores the trend and effect of these variables. India joined WTO as member in 1995. Since 
then, the possible consequences are being discussed and debated by the politicians and academic communities. Hence it is imperative to take the stock of 10 years membership of WTO and its impact on the agricultural growth.

The recently held WTO conference at Hong Kong remained inconclusive on the several issues and agenda of the developing countries. Dubey (2006) concludes that the claims made by the Indian negotiators are grossely exaggerated and some of them partially true. The biggest achievement of the conference is G-20 group is formed to pressurize the developed countries. However the outcome of this conference is that European Union (EU) countries agreed upon to eliminate the export subsidy by 2013. First up this entire deadline is seven years away from the 2006 and EU countries tactfully postponed it for 10 years. It shows the reluctance and dubious strategy pursued by the developed nation group countries against the developing countries.

Khor (2005) points that pounding pressure of the developed countries on developing countries for market entry into developing nations and to open up their agricultural, industrial and service sectors could not bring any success of the Doha round. In fact the low priority has been accorded to the implementation issues related to the Uruguay Round and Special and Differential Treatment (SDT), these were excluded from the list of discussions after the Cancun Conference 2003. Chand (2005) finds that pre-WTO and post-WTO reforms period shows decelerating and negative growth rates in 10 commodity groups out of 12. Exports have been adversely affected and imports had increased speedily. Food security and nutrition affected during the reforms period. The growth of food grain production dropped from 1.51 percent (1991-1995) to 1.17 percent in the WTO and reforms period (1996-2001) for India.

Sahu and Rajshekar (2005) reveal in their paper on State and Direction of Agricultural Credit to Indian Farmers, for the period 1981 to 2000 of Scheduled Commercial Banks (SCB). They found that the share of agriculture credit in total net bank credit had significantly eroded from 13.84 percent in the year 1990 to 8.38 per cent in 2000 after the introduction of banking sector reforms in India. Satish (2006) takes the review of institutional credit, indebtedness and suicides in Punjab and finds that the share of cooperative credit declined from 65.05 to 47.92 percent and that the share of commercial bank rose from 34.91 to 52.08 during the period 1990-91 to 2002-03. He also finds that the indebtedness is not due to the lack of institutional credit supply but it is an outcome of the excessive consumption expenditure and declined retunes from the agriculture. Shriram (2006) analyses the recommendations of task force on the revival of rural cooperative credit 
instuitions with his comments. His opinions that the state will not agree to clean up cooperatives due the vested interest and political reasons. Mathur and Das (2006) analyses the determinants of agricultural growth at all India level for the period 199091-2003-04 and concludes that the investment of government in agricultural sector; subsidy, agriculture prices and usage of electricity are the significant factors that decide the production flow of Indian agriculture.

\section{Data and Methodology}

We resort to the use of secondary data for this research paper. The main source of data for this study is based on the Handbook on Indian Statistics published by Reserve Bank of India, Mumbai. This study is made for the period 1970-71 to 2003-04 for which latest data is at hand at the respective sources. We splint the study period into three: 1970-71 through 1980-81; 1981-1982 through 1991-1992 and 1992-93 through 2003-04, to track the status of Indian agriculture before and after liberalization periods. To unearth the determinants of agricultural production before liberalization, after liberalization and after the WTO membership we used Cobb Douglas (CD) Production Function Methodology based on Ordinary Least Squares (OLS) for the above mentioned periods.

The relationship between agricultural inputs and output is documented in the various studies. Most of the earlier Indian and cross-country studies use Cobb Douglas (CD) production function to know the contribution of a particular input in the total production. Studies made earlier in India about the agriculture production function used inputs like land, labour, irrigation, fertilizers. For instance Kata (1990), Chadha (1979), Bagi (1980), Mathur, Pattnayak and Nayak (2005), and Das and Sircar (2006) are the most well received studies in which agricultural production function is empirically tested using the same methodology. In line with earlier studies, we use $\mathrm{CD}$ production function to trace the contribution of individual input in the production function. This methodology enables us to check the presence of Indian agricultural sector in the phase of production during the different periods. In our empirical Y study we used the following model:

$Y_{i}=\beta_{1}+C R_{2 i}^{\beta_{2}}+I R_{3 i}^{\beta_{3}}+F E_{4 i}^{\beta_{4}}+P E_{5 i}^{\beta 5}+P R_{6 i}^{\beta_{6}}+A R_{7 i}^{\beta 7}+e+\mu^{i}$

Where, $Y_{i}=$ Agricultural GDP, $\beta_{1}=$ Constant representing technological change, $C R=$ Institutional Credit to Agriculture, $I R=$ Net Irrigated Land, $F E=$ Consumption of Fertilizer, $P E=$ Use of Pesticides, $P R=$ Support Prices declared by the Central Government for Wheat 
is used as proxy variable for the Price level of other Agricultural Products, $A R=$ Net Area Sown, $e=$ Base of Natural Logarithm and $\mu=$ Stochastic Disturbance term,.

From the equation 1 relationship between output and input is nonlinear; however after log-transforming this model, we can have following linear model:

$$
\ln Y_{i}=\ln \beta_{1}+\beta_{2} \ln C R_{i}+\beta_{3} \ln I R_{i}+\beta_{4} \ln F E_{i}+\beta_{5} \ln P E_{i}+\beta_{6} \ln P R_{i}+\beta_{7} \ln A R_{i}+\mu_{i} \ldots . .2
$$

Where $\beta_{0}=\ln \beta_{1}$ thus equation 2 is linear in the parameters $\beta_{0}, \beta_{1}, \beta_{2}, \beta_{3}, \beta_{4}, \beta_{5}$ and $\beta_{6}$ is therefore Linear Regression Model and all parameters are the respective Elasticities. This model is also known as Log-Linear Model. The summation of above parameters gives information about returns to scale; it means that, the response of the output to proportionate change in inputs. If sum of these parameters is 1 , then it is assumed that there is a Constant Return to Scale, if the sum is less 1 it means there is Decreasing Returns to Scale and if the sum is greater than 1 it means there is Increasing Returns to Scale.

The variables used in the study are defined as follows. Institutional Credit to Agriculture (CR) comprises of direct (short-term and long-term) credit issued by Cooperative, State governments, Scheduled Commercial Banks and Regional Rural Banks to agriculture and allied sector in Crore Rupees. Irrigation Facility (IR) is the Net irrigated area under cultivation in million hectares. Consumption of Fertilizers (FE) includes $N+P+K$ in lakh tones. Use of Pesticide (PE) is the consumption of pesticides (technical grade material) in thousand tones. Wheat Support Price (PR) is used as proxy variable to denote price level of other agricultural commodities. Good support prices of food grain act as motivational factor to grow that variety on large scale. Wheat support price declared by agricultural price commission are captured. Wheat support price is in Indian Rupee terms. Net Area Sown (AR) Net Area brought under cultivation of the crops in million tones in used for framing this variable. Agricultural Gross Domestic Product (AGDP) is employed as Dependant variable $(Y)$ which acts as proxy for productivity of Indian agriculture. We use the old price series of 1993 of GDP at constant prices in Rupee (Crores) available at source of the data.

\section{Discussions}

In order to check for the determinants of Agricultural GDP, the present study uses six explanatory variables to find out its relationship with output. These determinants are: institutional credit, irrigation facility, consumption of fertilizer, use of pesticides and support price of the wheat. These explanatory variables determine the Agricultural GDP is shown in the four different models. Data on some of these variables is not reported after the year 2002 
at the source and hence our study is confined to the year 2002 only. The data on the variables like use of pesticides and support prices of wheat is not available in earlier years of study hence we drop them for the model 1 and model 2, however are retained in the subsequent models 3 and 4 . In our study we have not used Labour as variable due to the data limitation. Our study is thus limited due to unavailability of variables.

The cobb douglas production framework used in the empirical study to estimate the output elasticites of different variables. The value of elasticity measure the per cent change in agricultural gross domestic product (AGDP) with 1 percent change in explanatory variable. Each factor's (input) contribution in the total production function can be measured, holding other input constant. The sum of all $\beta_{2}+\beta_{3} \ldots \ldots \ldots \ldots(\operatorname{lnCR}+\operatorname{lnFR} \ldots \ldots)$ gives information about returns to scale, which is the response of output to a proportionate change in inputs. While measuring all $\beta$ coefficients we assume that $\alpha$ (intercept) i.e. technology remains constant.

\section{Table 3. Determinants of Agricultural Production in India using Cobb Douglas Production Function Methodology}

\begin{tabular}{|c|c|c|c|c|c|c|c|c|}
\hline Period & \multicolumn{2}{|c|}{ 1970-71 to 2002-03 } & \multicolumn{2}{|c|}{ 1970-71 to $1980-81$} & \multicolumn{2}{|c|}{\begin{tabular}{|l|l|}
$1981-82$ to $1991-92$ \\
\end{tabular}} & \multicolumn{2}{|c|}{$1992-93$ to $2002-03$} \\
\hline \multirow{2}{*}{ Models } & \multicolumn{2}{|c|}{ I } & \multicolumn{2}{|c|}{ II } & \multicolumn{2}{|l|}{ III } & \multicolumn{2}{|l|}{ IV } \\
\hline & Coefficient & $t$ & Coefficient & $t$ & Coefficient & $t$ & Coefficient & $t$ \\
\hline Constant & -3.60 & -1.10 & -8.95 & $-1.91 * * *$ & 0.55 & 0.24 & -6.58 & -0.47 \\
\hline $\mathbf{C R}$ & 0.21 & $3.45 * *$ & -4.98 & 0.32 & 0.14 & $2.84 * *$ & 0.11 & 0.99 \\
\hline IR & -0.12 & $-1.85 * * *$ & -0.12 & -0.98 & 0.13 & 1.51 & -4.20 & -0.18 \\
\hline FE & 0.50 & 1.27 & 0.35 & 1.27 & -0.26 & -0.4 & -0.20 & -0.16 \\
\hline PE & & & & & 0.18 & $1.94 * * *$ & -0.21 & -0.76 \\
\hline PR & 2.52 & $3.34 * *$ & 3.37 & $3.48 * *$ & 2.02 & $3.51 * *$ & 3.79 & 1.05 \\
\hline $\mathbf{A R}$ & & & & & -3.48 & 0.66 & 0.15 & 1.00 \\
\hline $\operatorname{Adj.} R^{2}$ & \multicolumn{2}{|c|}{0.97} & \multicolumn{2}{|c|}{0.79} & \multicolumn{2}{|l|}{0.98} & \multicolumn{2}{|l|}{0.95} \\
\hline$F$ & \multicolumn{2}{|c|}{325} & \multicolumn{2}{|c|}{9.67} & \multicolumn{2}{|c|}{110.56} & \multicolumn{2}{|l|}{32.91} \\
\hline$D / W$ & \multicolumn{2}{|c|}{0.99} & \multicolumn{2}{|c|}{1.88} & \multicolumn{2}{|c|}{2.35} & \multicolumn{2}{|l|}{2.36} \\
\hline$N$ & \multicolumn{2}{|l|}{32} & \multicolumn{2}{|c|}{10} & \multicolumn{2}{|l|}{11} & \multicolumn{2}{|l|}{11} \\
\hline Phase & \multicolumn{2}{|c|}{ IRS } & \multicolumn{2}{|c|}{ NRS } & \multicolumn{2}{|c|}{ NRS } & \multicolumn{2}{|l|}{ NRS } \\
\hline
\end{tabular}

Notes: Level of significance $*, * *, * * *$ are denoted as 1 per cent, 5 percent and 10 percent respectively. 1 . Dependant Variable $=\log$ of agricultural gross domestic product; 2. Independent Variables: $\mathrm{CR}=\log$ of institutional credit sources, IR $=\log$ of net irrigated area, $\mathrm{FE}=\log$ of consumption of fertilizers, $\mathrm{PE}=\log$ of use of pesticides, $\mathrm{PR}=\log$ of support price of wheat and $\mathrm{AR}=\log$ of net area sown; 3. Phases: IRS= Increasing Returns to Scale, $\mathrm{CRS}=\mathrm{Constant}$ Returns to Scale, NRS $=$ Negative Returns to Scale; $4 . F, D / W$ and $N$ denotes the $F$ Statistic, Durbin-Watson Statistic and Number of observations respectively.

Table 3 reveals the result of our analysis. We measure the four models for figuring the pre and post-liberalization determinants of production for the Indian agricultural sector. We also measure the production function for decade seventies to know the phase of 
production. Since 1970-71 several policy initiatives have been taken by the government of India and also the all the state governments to step up the production of food grains and for all-round development of Indian agricultural sector. Our analysis throws light on the two distinct queries; In which phase Indian agriculture sector was passing in the last three decades and especially the after the introduction of new economic policy 1991. It also explores the determinants of agricultural gross domestic product through the Cobb Douglas production function. The contribution of each variable reveals by looking at the coefficient of independent variable. Our exercise gives the policy guidance to the government for taking necessary steps to correct the existing policy frame work.

Model 1 (1970-71 to 2002-03) uses only four variables for measuring production function because we could not get complete data on remaining variables for the same period. Our results point that institutional credit and net area sown show positive and significant effect on the growth of AGDP. However the consumption of fertilizer has negative impact on AGDP. It means that though the consumption fertilizer increases by 1 percent, AGDP decreases by 1.22 percent. Irrigation facility has positive effect on production of AGDP but it remains statistically insignificant. The $\mathrm{R}$ square value of this model is 0.97 means that about 97 per cent of the variation in the log of the dependent variable is explained by the $\log$ of these four variables. This model shows that Indian agriculture has witnessed Increasing Returns to Scale stage for the period 1970-71 to 2002-03. Our finding is consistent as the total food grain production has increased by 300 per cent during the same period in India following the result of the new agricultural strategy pursued since 1966 periods.

Model II and III results display the Decreasing Returns to Scale stage observed for the decade seventies and eighties in the Indian agricultural sector. It also point out that the impact of new agricultural strategy has lost its continuity in the agricultural sector. Model II reveals that variable institutional credit and consumption of fertilizer shows negative elasticity, however irrigation facility and net area sown exhibit positive sign of elasticity. In this model only the net area sown shows positive significant elasticity in explaining AGDP. Model III is designed for examining the association between inputs and output before the 10 years of liberalization policy introduced in 1991-92. In the Model III, variables institutional credit, use of pesticides and net area sowed direct (statistically significant) positive association with the dependent variable. The variable consumption of fertilizer shows positive value of elasticity which is not statistically significant. Other remaining variables like net area irrigated and wheat support prices takes negative value of elasticity that means AGDP does not respond to these two variables in linear manner. Support prices declared by 
the government every year does not act as motivating factor to the farmers for expanding the cultivation of food grain crops in India. Our result of model III shows that Indian agriculture sector had witnessed the decreasing stage. The results of this model match with the findings of the earlier studies conducted for the similar periods.

Model IV is run for the period 1992-93 to 2002-03 to examine the impact of the new economic policy and India's membership of the WTO on the determinants of AGDP growth by adopting Cobb Douglas production function. There is widespread complaint and understanding that government of India has minimized the subsidy support to agriculture for reducing public expenditure under the pressure of WTO. Banking reforms have also forced the banks to curtail risk prone credit that banks give to the farmers. Against this backdrop we examined the elasticity values of various inputs and their respective contribution in agricultural growth. Our findings show that not a single input is statically significant in either a positive or negative way. The coefficient values of the variable like consumption of fertilizer, net irrigated area and use of pesticides takes the negative sign. This sign points out that their contribution in agricultural growth seems to be $-4.2,-0.2$, and -0.2 percent respectively. The sign of other variables like institutional credit sources, net area sown and support price of wheat takes positive value of elasticites with statically insignificant. A finding of this model can be concluded as Indian agricultural sector had witnessed decreasing retunes to scale as the contribution of these variables are found to be insignificant. This might have resulted due to weak supply of inputs to agricultural sector during the period. Our results based on model IV advocates that there is urgent need to build a capacity of all necessary inputs to meet the problem of food security and for all round development of this sector.

\section{Conclusions and Policy Implication}

The over all findings of our empirical exercise can be drawn from models II through IV and shows that Indian agricultural sector had witnessed the Decreasing Returns to Scale phase in the decade of seventies, eighties and nineties. However, model I (1971-72 to 200203) shows the phase of Constant Returns to Scale. Another observation is that, among all the models, institutional credit and net area sown bears the statistically significant association with agricultural growth except for the model IV. Rest all the variables used in our models displays correct signs but is statistically insignificant. Before and after the introduction of the New Economic Policy, Indian agriculture sector is in the Decreasing Returns to Scale phase. This finding proves that input availability was under strain during that period, hence there is 
urgent need to increase the flow of agro-inputs to meet the global challenge of food security, poverty reduction and unemployment. We therefore advocate government to increase the flow of inputs to this sector so that the proposed 10 percent growth rate can be achieved successfully.

\section{References}

Dubey Mukchand (2006), 'WTO Hong Kong Conference: An Appraisal', Economic and Political Weekly, Vol. XCI 1, Pp 15-19.

Government of India (2006), Economic Survey, Ministry of Finance, New Delhi

Kalamkar, S.S., and Narayanmurthy, A. (2003), 'Impact of Liberlisation on Domestic Agricultural prices and farm Income', Indian Journal Agricultural Economics, Vol.3, Pp 353-364.

Khor Martin (2006), 'Impasse at the WTO: A Development Perspective', Economic and Political Weekly, Vol. XLI 45, Pp 4659-4667.

Levis, W. A. (1954), Economic Development with Unlimited Supplies of Labour, Manchester School of Economics and Social Studies, 22.

Majumdar, N.A. (2006), 'Centrality of Agriculture to India's Economic Development', Economic and Political Weekly, Vol. XCI 1, Pp 31-34.

Mathur, A. S., Das Surjit and et al (2006), 'Status of Agriculture in India: Trends and Prospects', Economic and Political Weekly, Pp 5327-5336.

Narayanmurthy, A. (2006), 'State of India's Farmers', Economic and Political Weekly, Vol. XLI 6, Pp 471-473.

Pal, Parthapratius, (2004), WTO Agreement on Agriculture and Its Impact on Employment in South Asia, Paper submitted for Global Development Network Organized Conference, Pp $1-29$.

Pujari, Ayan Kumar (2004), Regional Variation in Cereal Production in India, paper presented at Indian Econometric Society Conference at ICES, Bangalore, Pp 1-25.

Patnayak M., and Nayak B.P. (2005), Performance of Agriculture in the Changing Structure of the Orissa Economy: Issues Revisited, Paper presented at $40^{\text {th }}$ Annual Conference of the Indian Econometric Society of India, Pp 1-23.

Reserve Bank of India (2006), Hand Book on Indian Statistics, Dept of Economic Policy and Research, Mumbai. 
Sahu, G. B., and Rajshekar, D. (2005), 'Banking Sector Reform and Credit Flow to Indian Agriculture', Economic and Political Weekly, vol. XL 53, Pp 5550-5559.

Satish, P. (2006), 'Institutional Credit, Indebtedness and Suicides in Punjab', Economic and Political Weekly, Vol. XLI 26, Pp 2754-2761.

Shriram, M. S. (2006), 'Reviving Cooperative Credit Institutions', Economic and Political Weekly, Vol. XLI 4, Pp 298-300.

Sidhu, R. S., and Bhullar, A.S., (2005), 'Pattern and Determinants Agricultural Growth in the Two Punjab', Economic and Political Weekly, Vol. XL 53, Pp 5620-5627.

Syrquin, M. (1988), 'Pattern of Structural Change' in Hollis Chenery and T.S. Srinivasan (eds), Handbook of Development Economics, Vol, I, Elesevier Science Publishers, Ameserdam. 